Pacific Journal of Mathematics

RINGS OF FUNCTIONS WITH CERTAIN LIPCHITZ 


\title{
RINGS OF FUNCTIONS WITH CERTAIN LIPSCHITZ PROPERTIES
}

\author{
C. H. SCANLON
}

Let $(X, d)$ denote a metric space, $L_{c}(X)$ the ring of real valued functions on $X$ which are Lipschitz on each compact subset of $X, L_{1}(X)$ the ring of real valued functions on $X$ which are locally Lipschitz relative to the completion of $X$, and $L_{c}{ }^{*}(X), L_{1}{ }^{*}(X)$ the bounded elements of $L_{c}(X), L_{1}(X)$. The relations between equality of these rings and the topological properties of $X$ are studied. It is shown that a subspace $(S, d)$ of $(X, d)$ is $L_{c}$-embedded (or $L_{c}{ }^{*}$-embedded) in $(X, d)$ if and only if $S$ is closed. Further, every subspace of $(X, d)$ is $L_{1}$ and $L_{1}{ }^{*}$-embedded in $(X, d)$.

Su [3] investigated algebraic properties of the rings $L_{c}(X)$ and $L_{c}^{*}(X)$ similar to those of $C(X)$ and $C^{*}(X)$ by Gillman and Jerrison [2].

2. Equality of rings. Let $f$ denote a real valued function defined on $X . \quad f$ is Lipschitz on $S \subset X$ if and only if there is a real number $m$, called a Lipschitz constant for $f$ on $S$, such that if $x$, $y \in S$, then $|f(x)-f(y)| \leqq m d(x, y)$. $f$ is locally Lipschitz on $X$ if and only if for each $x \in X$, there is a neighborhood $N$ of $x$ such that $f$ is Lipschitz on $N$. If comp $X$ denotes the completion of $X$, then $f$ is locally Lipschitz with respect to comp $X$ if and only if for each $x \in \operatorname{comp} X$ there is a neighborhood $N$ of $x$ such that $f$ is Lipschitz on $N \cap X$.

TheOREM 2.1. $f \in L_{c}(X)$ if and only if $f$ is locally Lipschitz on $X$.

Sufficiency. Let $f$ be locally Lipschitz on $X$ and $S$ a compact subset of $X$. Then there exists a finite collection $N_{1}, N_{2}, \cdots, N_{m}$ of open sets covering $S$, on each of which $f$ is Lipschitz and thus bounded. Assuming $f$ is not Lipschitz on $S$ implies that there exists a sequence $\left\{x_{n}\right\}$ from $S$ converging to $x \in S$ and a sequence $\left\{y_{n}\right\}$ from $S$ such that $\left|f\left(x_{n}\right)-f\left(y_{n}\right)\right| / d\left(x_{n}, y_{n}\right)>n$ for each positive integer $n$. Since $f$ is bounded on $S$, it follows that $\left\{y_{n}\right\}$ converges to $x$. Since $x \in N_{j}$ for some $j=1,2, \cdots, m, f$ is not Lipschitz on $N_{j}$ which contradicts the definition of $N_{j}$.

Necessity. Let $f \in L_{c}(X)$ and $x \in X$. Assuming $f$ is not locally Lipschitz at $x$ implies there exists sequences $\left\{x_{n}\right\}$ and $\left\{y_{n}\right\}$ such that 
$d\left(x, x_{n}\right)<1 / n, d\left(x, y_{n}\right)<1 / n$, and $\left|f\left(x_{n}\right)-f\left(y_{n}\right)\right| / d\left(x_{n}, y_{n}\right)>n$. Then $\left\{p: p \in\left\{x_{n}\right\}, p \in\left\{y_{n}\right\}\right.$, or $\left.p=x\right\}$ is a compact subset of $X$ on which $f$ is not Lipschitz.

CoROLlary 2.2. $f \in L_{c}^{*}(x)$ if and only if $f$ is locally Lipschitz on $X$ and bounded.

Proof. Follows immediately from the definition of $L_{c}^{*}(X)$.

CoROLlaRY 2.3. $L_{1}(X) \subset L_{c}(X)$ and $L_{1}^{*}(X) \subset L_{c}^{*}(X)$.

Proof. If $f$ is locally Lipschitz relative to $\operatorname{com} X$, then $f$ is locally Lipschitz.

LEMma 2.4. If $K$ is a uniformly bounded set of Lipschitz functions defined on $S \subset X$ and there is a real number $m$ which is a Lipschitz constant for each element of $K$, then $f(x)=\sup \{g(x): g \in K\}$ for each $x \in S$ is Lipschitz on $S$ and $m$ is a Lipschitz constant for $f$ on $S$.

Proof. $f$ exists since $K$ is a uniformly bounded set. Assume $x \in S, y \in S$, and

$$
f(y)-f(x)-m d(x, y)=e>0 .
$$

Let $g \in K$ such that

$$
f(y)-g(y)<e,
$$

then

$$
g(y)-g(x) \leqq m d(x, y) \text {. }
$$

Combining (2) and (3) yields $f(y)-g(x)-m d(x, y)<e$, which when combined with (1) gives $f(x)<g(x)$. This contradicts the definition of $f$.

Lemma 2.5. Suppose each of $c$ and $r>0, p \in X$, and for

$$
\text { each } x \in X, f(x)=\left\{\begin{array}{l}
(c / r)\{r-d(x, p)\} \quad \text { for } \quad d(x, p) \leqq r, \\
0 \text { otherwise }
\end{array}\right.
$$

then $f$ is Lipschitz on $X$ and $(c / r)$ is a Lipschitz constant for $f$ on $X$.

Proof. Let $g(x)=(c / r)\{r-d(x, p)\}$ for each $x \in X$. Then for $x$, $y \in X$, 


$$
\begin{aligned}
& g(x)-g(y)=g(x)-g(p)+g(p)-g(y), \\
& g(x)-g(y)=-(c / r) d(x, p)+(c / r) d(y, p),
\end{aligned}
$$

and $g(x)-g(y) \leqq(c / r) d(x, y)$ by the triangle property. Since $\sup \{g, 0\}$ is Lipschitz with a Lipschitz constant $\sup \{(c / r), 0\}$ by Lemma 2.4 , the conclusion follows.

THEOREM 2.6. Each of the following is equivalent to each of the others:

(1) $L_{1}(X)=L_{c}(x)$,

(2) $L_{1}^{*}(X)=L_{c}^{*}(X)$, and

(3) $X$ is complete.

Proof. $\quad(1) \Longrightarrow(2)$ obviously. The remaining order is $(2) \Longrightarrow(3) \Longrightarrow(1)$.

Assume (2) and that $X$ is not complete. Then there exists an $x \in(\operatorname{comp} X)-X$ and a sequence $\left\{x_{n}\right\}$ of distinct points in $X$ such that $\left\{x_{n}\right\}$ converges to $x$. For each odd integer $n$, let

$$
\begin{aligned}
& r_{n}=\frac{1}{3} \inf \left\{y: y=d\left(x_{n}, x_{m}\right) \text { for } m \neq n \text { or } y=(1 / n)\right\}, \\
& C\left(x_{n}, r_{n}\right)=\left\{t \in X: d\left(t, x_{n}\right) \leqq r_{n}\right\},
\end{aligned}
$$

and

$$
f_{n}(t)=\left\{\begin{array}{l}
\left(1 / r_{n}\right)\left\{r_{n}-d\left(x_{n}, t\right)\right\} \text { for } t \in C\left(x_{n}, r_{n}\right) \\
0 \quad \text { otherwise }
\end{array}\right.
$$

for each $t \in X$. Let $f(t)=\sup \left\{f_{n}(t)\right\}$ for each $t \in X$. If $S$ is a compact subset of $X$, then $S$ can intersect at most a finite number of the elements of $\left\{C\left(x_{n}, r_{n}\right)\right\}$ and since only a finite number of elements of $\left\{f_{n}\right\}$ are nonzero on $S$, by Lemma $2.4 f$ is Lipschitz on $S$ and $f \in L_{c}^{*}(X)$. For each neighborhood $N$ in comp $X$ of $x$, there is a point $t \in N$ and a point $y \in N$ such that $f(t)=1$ and $f(y)=0$. Thus $f \notin L_{1}(X)$ and by contradiction, $(2) \Longrightarrow(3)$.

If (3) is true, $f \in L_{1}(X)$ if and only if $f$ is locally Lipschitz. Thus by Theorem 2.1, $L_{1}(X)=L_{c}(X)$ and $(3) \Longrightarrow(1)$.

TheOREm 2.7. $L_{c}(X)=L_{c}^{*}(X)$ if and only if $X$ is compact.

Proof. If $X$ is compact, then each element of $L_{c}(X)$ is bounded. Assume $L_{c}(X)=L_{c}^{*}(X)$ and $X$ is not compact. Then there exists a sequence $\left\{x_{n}\right\}$ of distinct points in $X$ which has no convergent subsequence. Let

$$
r_{n}=\frac{1}{3} \inf \left\{y: y=d\left(x_{n}, x_{m}\right) \text { for } n \neq m \quad \text { or } \quad y=\frac{1}{n}\right\},
$$


and

$$
f(x)=\left\{\begin{array}{l}
\left(n / r_{n}\right)\left\{r_{n}-d\left(x_{n}, x\right)\right\} \text { for } d\left(x_{n}, x\right) \leqq r_{n} \\
0 \quad \text { otherwise }
\end{array}\right.
$$

for each $x \in X$. By an argument similar to the one for Theorem 2.6, $f \in L_{c}(X)$. Since $f\left(x_{n}\right)=n$ for each $n, f \in L_{c}(X)-L_{c}^{*}(X)$ which contradicts the assumption.

Theorem 2.8. $L_{1}(X)=L_{1}^{*}(X)$ if and only if comp $X$ is compact.

Proof. Each element of $L_{1}(X), L_{1}^{*}(X)$ can be uniquely extended to an element of $L_{1}(\operatorname{comp} X)=L_{c}(\operatorname{comp} X), L_{1}^{*}(\operatorname{comp} X)=L_{c}^{*}(\operatorname{comp} X)$. Since $L_{c}(\operatorname{comp} X)=L_{c}^{*}(\operatorname{comp} X)$ if and only if $\operatorname{comp} X$ is compact by Theorem 2.7, the conclusion follows.

3. If $A$ denotes one of $L_{1}, L_{1}^{*}, L_{c}, L_{c}^{*}$ and $S \subset X$, then the statement that $S$ is $A$-embedded in $X$ means that if $f \in A(S)$, there is a $g \in A(X)$ such that $g \mid S=f$ where $g \mid S=\{(x, y) \in g: x \in S\}$.

THEOREM 3.1. If $S$ is a subset of $X$, then each of the following is equivalent to each of the others:

(1) $S$ is $L_{c}$-embedded in $X$,

(2) $S$ is $L_{c}^{*}$-embedded in $X$, and

(3) $S$ is closed.

Proof. Czipszer and Geher [1] proved that if $S$ is a closed subset of $X$ and $f$ is a real valued locally Lipschitz function with domain $S$, then there is a real valued locally Lipschitz function $g$ with domain $X$ such that $g \mid S=f$. Furthermore, they proved that if $f$ is bounded, then there exists a bounded such $g$. Consequently, by Theorem 2.1, $(3) \Rightarrow(1)$ and $(3) \Rightarrow(2)$.

Assume (2) and $S$ is not closed. Then there exists a sequence $\left\{x_{n}\right\}$ of distinct points in $S$ and a point $x \in X-S$ such that $\left\{x_{n}\right\}$ converges to $x$. Construct $f$ as in Theorem 2.6. Then $f \in L_{c}^{*}(S)$ which has no extension to $X$ in $L_{c}(X)$. Thus $(2) \Rightarrow(3)$. Note that this also shows $(1) \Rightarrow(3)$.

Corollary 3.2. Every subset of $X$ is $L_{1}$-embedded and $L_{1}^{*}$-embedded in $X$.

Proof. If $S \subset X$, then every element of $L_{1}(S)$ has a unique extension to the closure of $S$ in comp $X$ and by Theorems 2.6 and 3.1 
an extension in $L_{1}(\operatorname{comp} X)$ which when restricted to $X$ is an element of $L_{1}(X)$.

\section{REFERENCES}

1. J. Czipszer and L. Geher, Extension of functions satisfying a Lipschitz condition, Acta Math. Acad. Sci. Hungaricea 6 (1955), 213-219.

2. L. Gillman and M. Jerison, Rings of continuous functions, D. Van Nostrand, New Jersey, 1960.

3. Li Pi Su, Algebraic properties of certain rings of continuous functions, Pacific J. Math. 27 (1968), 175-191.

Received April 3, 1969.

THE UNIVERSity OF OKLAHOMA 



\section{PACIFIC JOURNAL OF MATHEMATICS}

\section{EDITORS}

\author{
H. SAMELSON \\ Stanford University \\ Stanford, California 94305 \\ Richard Pierce \\ University of Washington \\ Seattle, Washington 98105
}

J. DUGUNDJI

Department of Mathematics

University of Southern California

Los Angeles, California 90007

BASIL GORDON*

University of California

Los Angeles, California 90024

\section{ASSOCIATE EDITORS}
E. F. BECKENBACH
B. H. NeUmanN
F. WOLF
K. YoSHIDA

\section{SUPPORTING INSTITUTIONS}

UNIVERSITY OF BRITISH COLUMBIA CALIFORNIA INSTITUTE OF TECHNOLOGY

UNIVERSITY OF CALIFORNIA MONTANA STATE UNIVERSITY

UNIVERSITY OF NEVADA

NEW MEXICO STATE UNIVERSITY

OREGON STATE UNIVERSITY

UNIVERSITY OF OREGON

OSAKA UNIVERSITY

UNIVERSITY OF SOUTHERN CALIFORNIA
STANFORD UNIVERSITY

UNIVERSITY OF TOKYO

UNIVERSITY OF UTAH

WASHINGTON STATE UNIVERSITY

UNIVERSITY OF WASHINGTON

AMERICAN MATHEMATICAL SOCIETY CHEVRON RESEARCH CORPORATION TRW SYSTEMS

NAVAL WEAPONS CENTER 


\section{Pacific Journal of Mathematics}

\section{Vol. 32, No. $1 \quad$ January, 1970}

Robert Alexander Adams, Compact Sobolev imbeddings for unbounded domains ........................................ 1

Bernhard Amberg, Groups with maximum conditions .................. 9

Tom M. (Mike) Apostol, Möbius functions of order k............... 21

Stefan Bergman, On an initial value problem in the theory of two-dimensional transonic flow patterns ................... 29

Geoffrey David Downs Creede, Concerning semi-stratifiable spaces ...... 47

Edmond Dale Dixon, Matric polynomials which are higher

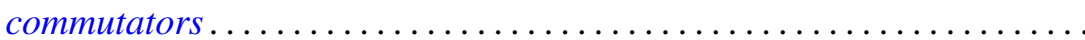

R. L. Duncan, Some continuity properties of the Schnirelmann density.

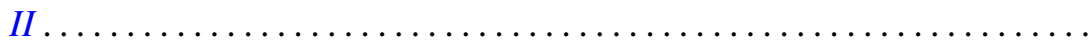

Peter Larkin Duren and Allen Lowell Shields, Coefficient multipliers of $H^{p}$

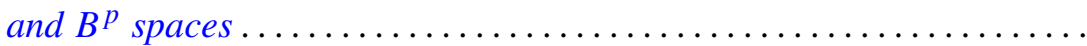

Hector O. Fattorini, On a class of differential equations for vector-valued

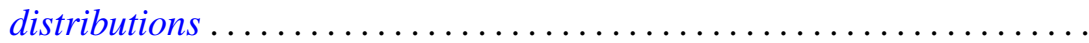

Charles Hallahan, Stability theorems for Lie algebras of derivations. . . . . . 105

Heinz Helfenstein, Local isometries of flat tori ................ 113

Gerald J. Janusz, Some remarks on Clifford's theorem and the Schur

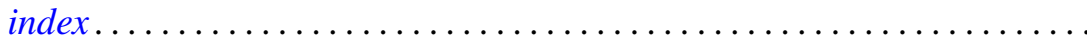

Joe W. Jenkins, Symmetry and nonsymmetry in the group algebras of discrete groups. ...

Herbert Frederick Kreimer, Jr., Outer Galois theory for separable

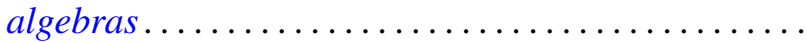

D. G. Larman and P. Mani, On visual hulls

R. Robert Laxton, On groups of linear recurrences. II. Elements of finite order.

Dong Hoon Lee, The adjoint group of Lie groups ...

James B. Lucke, Commutativity in locally compact rings

Charles Harris Scanlon, Rings of functions with certain Lipschitz

$$
\text { properties ............................... }
$$

Binyamin Schwarz, Totally positive differential systems .

James McLean Sloss, The bending of space curves into piecewise helical curves.

James D. Stafney, Analytic interpolation of certain multiplier spaces ...

Patrick Noble Stewart, Semi-simple radical classes.......

Hiroyuki Tachikawa, On left $\mathrm{QF}-3$ rings ...................... 255

Glenn Francis Webb, Product integral representation of time dependent nonlinear evolution equations in Banach spaces.... . . . 